\title{
Supuestos prácticos en trabajo social: diseño para su resolución
}

\section{Charo Ovejas}

Facultad de Relaciones Laborales y Trabajo Social, Universidad del País Vasco/Euskal Herriko Unibertsitatea (UPV/EHU) charo.ovejas@ehu.eus

\author{
Ainhoa Berasaluze \\ Facultad de Relaciones Laborales y Trabajo Social, \\ Universidad del País Vasco/Euskal Herriko Unibertsitatea (UPV/EHU) \\ ainhoa.berasaluze@ehu.eus
}

\begin{abstract}
Gizarte-langintzan suposizio praktikoak esku-hartze profesionalaren inguruan hausnartzea ahalbidetzen duten tresna teoriko-praktikoak dira. Hortaz, interesa daukate, bai eremu akademikoan eta baita eremu profesionalean ere. Eremu akademikoari dagokionez, irakaskuntza-ikaskuntza metodologia aktiboen gauzapenean lagungarriak dira. Eremu profesionalean aldiz, praxiaren hobekuntzarako eta prozesu hautatzaileen prestakuntzarako interesgarriak dira. Artikulu honek, hurbilpen kontzeptuala egin ondoren, suposizio praktikoen garapenerako beharrezkoak diren bi elementuei heltzen dio, eredu teorikoari eta prozesu metodologikoari, hain zuzen ere. Hau guztia oinarri izanik, ebazpenerako diseinu proposamen bat egiten da eta ondoren, Gizarte Zerbitzuen Euskal Sistemaren testuinguruan, suposizio praktiko zehatz baten aplikazioa garatzen da.
\end{abstract}

\section{GAKO-HITZAK:}

Suposizio praktikoa, gizarte-langintza, eredu teorikoa, prozesu metodologikoa.
Los supuestos prácticos en trabajo social son instrumentos teórico-prácticos que permiten la reflexión en torno a la intervención profesional. En este sentido, son de interés en el ámbito académico para el desarrollo de metodologías activas de enseñanza-aprendizaje y, en el ámbito profesional, para la mejora de la praxis y la preparación de procesos selectivos. El artículo aporta una aproximación conceptual a los supuestos prácticos para posteriormente hacer hincapié en los dos elementos necesarios para su abordaje: modelo teórico y proceso metodológico. Con base en ello, se propone un diseño para su resolución, así como la aplicación a un supuesto concreto en el contexto del Sistema Vasco de Servicios Sociales.

\section{Palabras Clave:}

Supuesto práctico, trabajo social, modelo teórico, proceso metodológico. 


\section{Premisas de partida}

Los supuestos prácticos en trabajo social son instrumentos teórico-prácticos que permiten reflexionar en torno a la intervención profesional. Al respecto, con el objetivo de clarificar la propuesta que se presenta en este artículo, es necesario realizar algunas aclaraciones y apreciaciones que se incluyen en las siguientes premisas:

a. La resolución de supuestos prácticos en trabajo social requiere una reflexión teórico-práctica que dirija la estrategia de intervención. La experiencia profesional es un valor añadido que proporciona “saberes prácticos", pero no es suficiente. El abordaje de supuestos requiere conocimientos teóricos previos y actualizados, relativos a modelos teóricos, metodología y técnicas de intervención, marco legislativo, contexto institucional, recursos, etc. En este sentido, a lo largo del artículo, se indican referentes bibliográficos como material de apoyo.

b. El supuesto práctico se refiere al diseño teórico de la intervención profesional, no a la intervención profesional propiamente dicha. En la resolución de supuestos, la experiencia profesional puede ser una fortaleza, pero también puede convertirse en una debilidad si se equipara el ejercicio profesional cotidiano con el diseño del supuesto. En este sentido, es importante tener en cuenta que la resolución de un supuesto práctico implica la toma de decisiones con información escasa y en ocasiones poco clara, por lo que, para avanzar en la resolución, habrá que presuponer algunas cuestiones haciéndolas explícitas.

c. Toda intervención profesional en trabajo social, y por ende el supuesto práctico, debe contemplar la especificidad disciplinar ${ }^{1}$. El supuesto práctico no es un instrumento exclusivo de trabajo social, otros perfiles profesionales también hacen uso de este (educación social, psicología, etc.). Por ello, la resolución de supuestos prácticos debe contemplar la especificidad profesional. Así, en trabajo social, el diseño de la intervención debe ser integral, superando la gestión y tramitación de recursos. Debe considerar las diferentes dimensiones del objeto y la diversidad de áreas que lo conforman. Además, el enfoque debe ser globalizador, contemplando tanto la dimensión personal (individual-familiar) como la colectiva (grupal-comunitaria).

d. Los supuestos prácticos son de interés tanto para el ámbito académico, como para el ámbito profesional. El objetivo principal de este artículo es ofrecer un diseño que permita reflexionar en torno a la praxis profesional. No obstante, a pesar de que el contenido no ha sido pensado expresamente para la preparación de oposiciones, puede resultar de ayuda para preparar procesos selectivos (OPE, bolsas de

${ }^{1}$ Una buena definición de la especificidad disciplinar del trabajo social la podemos encontrar en la obra recopilatoria de la catedrática en Trabajo Social Teresa Zamanillo (2018). trabajo, etc.), ya que se ofrece una aproximación teórica al diseño de la intervención profesional que permite estructurar los conocimientos teórico-prácticos y con ello afrontar exámenes y pruebas de evaluación ${ }^{2}$. En este caso, la resolución de supuestos requiere también conocimientos teórico-legislativos (temarios específicos), el conocimiento de las competencias de la Administración concreta y de las funciones y tareas del puesto al que se opta. Asimismo, puede ser de ayuda conocer los procedimientos de actuación establecidos por la institución a través de los sistemas informáticos.

Desde estas consideraciones, el artículo aporta una aproximación conceptual a los supuestos prácticos, para posteriormente hacer hincapié en los dos elementos necesarios para su abordaje: modelo teórico y proceso metodológico. Con base en ello, se propone un diseño para su resolución, así como la aplicación a un supuesto concreto en el contexto del Sistema Vasco de Servicios Sociales (SVSS).

\section{Conceptualización de supuestos prácticos}

Un supuesto práctico es una simulación de una situación, real o hipotética, que incluye una o varias situaciones habituales en la intervención social. Se elabora a partir de una situación de la práctica profesional, con un marco institucional de referencia, y alude a situaciones de malestar psicosocial, vulnerabilidad, riesgo o desprotección, proceso de exclusión social, etc. que aconsejan una intervención profesional para su mejora.

El supuesto es una herramienta de carácter analítico, divisible en partes, que permite la reflexión sobre una situación con una solución incierta, constituyendo un instrumento que relata de forma secuencial la intervención profesional. De acuerdo con Francisco García, el supuesto práctico es:

El instrumento que opera sobre una historia social completa, real o hipotética, donde se relata de forma secuencial la intervención profesional que se realizaría ante una situación social, determinada por un conjunto de variables donde se identifican o infieren problemas o necesidades sociales y el o la trabajadora social debe dar respuestas planteando estrategias y ofreciendo soluciones en su desarrollo (García, 2001: 134).

${ }^{2}$ Con respecto a las pruebas selectivas, cabe recordar que cada tribunal calificador o comisión evaluadora es única e irrepetible y tiene poder de decisión respecto al tipo de pruebas y a los criterios de corrección. Entre las pruebas prácticas, la resolución completa de un supuesto es solo una opción. De hecho, en los últimos exámenes realizados en la Comunidad Autónoma del País Vasco, la mayoría de las pruebas se han centrado en preguntas relativas a alguna fase de la resolución de supuestos, por ejemplo: "Cita las demandas explícitas e implícitas"; "Elabora el genograma"; "Indica que información sería necesaria recabar"; "Elabora el diagnóstico social”; “Diseña el plan de intervención”; “¿Que ayudas económicas y recursos sociales pueden aplicarse en este supuesto?”; etc. 
El aspecto esencial en la resolución de supuestos prácticos es la coherencia interna, lo que supone una intervención lógica (con encadenamiento regular y razonable de las cosas, hechos o ideas vinculadas a la realidad social a transformar), racional (respondiendo a la razón, es decir, a un pensar, sentir y actuar, coherente con los datos de la experiencia y los principios organizadores del análisis) e interrelacionada (con correspondencia mutua entre partes, fases, etapas).

Asimismo, los contenidos incluidos en la resolución del supuesto deben cumplir los siguientes requisitos:

- Actuales, tanto en la legislación y en los recursos sociales, como en lo relativo a las situaciones sociales, los modelos teóricos, etc.

- Pertinentes, incluyendo solo aquellos conocimientos necesarios para la resolución del supuesto, evitando la inclusión de información superflua.

- Viables, considerando en todo caso el marco institucional en el que se plantean.

- Técnicos y profesionales, integrando conocimientos y contenidos disciplinares.

Como se indicaba anteriormente, los supuestos prácticos son de especial interés tanto para el ámbito docente como para el ámbito profesional, ya que permite poner en relación teoría y práctica, acción y reflexión. Sin embargo, según el ámbito donde se desarrollen tienen un sentido diferente:

- En el ámbito académico, el supuesto práctico es un instrumento pedagógico. Su objetivo es doble, acercar la intervención profesional a las aulas y desarrollar competencias cognitivas, procedimentales y actitudinales: "saber, saber hacer y saber ser”. En este ámbito, los supuestos prácticos forman parte de los ejercicios y de las pruebas de evaluación de asignaturas.

- En el ámbito profesional, el supuesto práctico es un instrumento operativo. Permite analizar los elementos del proceso de intervención desde un referente teórico, con el fin de mejorar la práctica profesional. En este ámbito los supuestos prácticos se convierten en herramientas de formación continua, de especial interés en procesos de supervisión profesional.

Respecto a las tipologías de supuestos prácticos, teniendo en cuenta el grado de complejidad y el nivel de concreción de la estrategia de acción profesional, se hace referencia a tres instrumentos: plan, programa y proyecto, reflejando los niveles estratégico, táctico y operativo de la intervención. Un supuesto práctico podría referirse a los diferentes niveles estratégicos, no obstante, lo habitual es que se refieran a proyectos, a la intervención sobre una situación concreta, que se desarrollará a través de diferentes actividades y tareas ${ }^{3}$.

3 Un buen manual para la formulación de proyectos sociales es el de Gustavo García y José Manuel Ramírez (2006).
Por otro lado, tomando como referencia la práctica profesional cotidiana y con ello los niveles básicos de intervención, se pueden distinguir dos tipos de supuestos, individual-familiar y grupal-comunitario. En algunas ocasiones el supuesto es mixto, englobando los dos anteriores. También pueden ser sectoriales, refiriéndose a colectivos concretos con necesidades sociales específicas y también vinculados a los distintos sistemas de protección social, abordando en ambos casos situaciones individuales-familiares y colectivas.

Independientemente de los niveles de intervención, la atención a la persona debe realizarse desde la globalidad, incorporando la perspectiva comunitaria. Lo adecuado es una intervención pluridimensional, contemplando junto a la dimensión individualfamiliar, la dimensión colectiva y con ello, las circunstancias sociocomunitarias: la red personal, la familiar y la social.

La propuesta presentada en este artículo ofrece un diseño aplicable a cualquier tipo de supuesto práctico, independientemente de las tipologías señaladas. No obstante, siempre es necesario considerar las peculiaridades propias de cada nivel de intervención ${ }^{4}$.

\section{Elementos constitutivos: modelo teórico y proceso metodológico}

Para la resolución de supuestos prácticos, tanto el modelo teórico como el proceso metodológico son elementos clave. Mientras que el proceso metodológico tiene un carácter instrumental, el modelo teórico supone una elección entre diferentes opciones, en coherencia con los principios y valores del trabajo social. Ambos elementos están interrelacionados, ya que junto a cualquier proceso de desarrollo metodológico no podemos obviar la consideración de un modelo teórico de referencia.

Modelo y método son dos elementos complementarios e inseparables en la acción profesional, fundamentales ambos, pero insuficientes si se utilizan aisladamente: no es correcto servirse de un modelo teórico sin introducirlo en un proceso metodológico, del mismo modo que no es posible llevar adelante este proceso sin tomar como punto de referencia un modelo (Campanini y Luppi, 1995: 17).

La aplicación del método básico de trabajo social desde un enfoque teórico determinado es, precisamente, una característica diferenciadora del

${ }^{4}$ Para profundizar sobre los niveles de intervención pueden ser referentes bibliográficos de interés los siguientes: para el nivel individual-familiar, Tomás Fernández y Laura Ponce de León (2018), para el nivel grupal, Teresa Zamanillo (2008) y para el nivel comunitario, Enrique Pastor (2015). 


\section{Supuesto práctico en trabajo social}
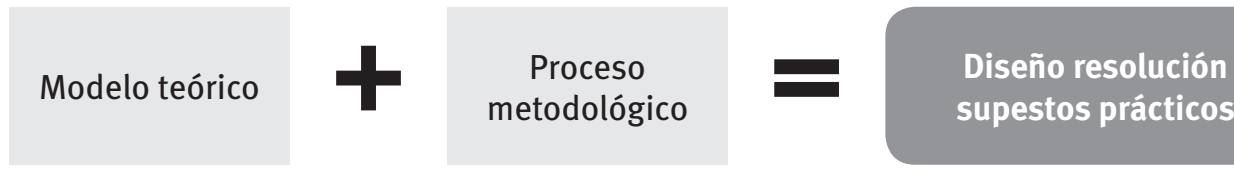

Fuente: Elaboración propia.

diseño que se propone ${ }^{5}$. La orientación y contenido de cada una de las fases del proceso metodológico, está condicionada por la concepción e ideología de los y las profesionales que lo utilizan, marcando líneas y estrategias de intervención, acordes al modelo elegido. De este modo, para el abordaje de supuestos prácticos se deben considerar ambos elementos, integrándolos en el diseño para su resolución, tal como se muestra en el Cuadro 1.

\subsection{Modelo teórico}

El modelo teórico es una guía, una construcción racional que orienta la interpretación de la realidad social y de la intervención profesional, proporcionando coherencia a la praxis y orientando tanto los objetivos como las líneas de acción. En este sentido Viscarret dice:

El concepto de modelo en trabajo social integra en un todo, en una unidad, todos los aspectos que forman parte de una intervención social: los aspectos teóricos, metodológicos, funcionales y también filosóficos, de una determinada forma de llevar a cabo la práctica profesional [...] el modelo sirve de soporte explicativo de la realidad y del problema al que se enfrenta el profesional, al mismo tiempo que le sirve de guía para la evaluación de la eficacia de la acción (Viscarret, 2009: 300).

Probablemente, los modelos teóricos más utilizados por las trabajadoras y los trabajadores sociales hayan sido el modelo psicosocial y el modelo sistémico ${ }^{6}$, mientras que el modelo de gestión de casos ha tenido una mayor influencia en el sistema de servicios sociales?.

${ }^{5}$ Junto a la metodología, el modelo teórico es un referente esencial en la resolución de supuestos prácticos. Manuales sobre supuestos prácticos en trabajo social, tanto clásicos como recientes, ofrecen una adecuada orientación metodológica, sin embargo, el modelo teórico no es un referente en su aplicación (García, 2001; Mosquera, 2014; García, 2015; Aliseda, 2019).

${ }^{6}$ Para una aproximación a los principales modelos teóricos en trabajo social se puede consultar Viscarret (2007)

7 La obra de Fernando Fantova, que comparte de manera abierta en su blog (http://fantova.net), y la página web del SIIS Centro de Documentación y Estudios (https://www.siis.net/) son fuentes de
Así, el modelo teórico puede venir condicionado por factores vinculados al contexto institucional en el que el trabajador o trabajadora social desarrolla su trabajo. En este sentido, en especial en el caso de oposiciones o pruebas selectivas, será necesario conocer el modelo de atención propuesto por la institución en la que se desarrolla o contextualiza el supuesto práctico. Por todo ello, en el contexto de la Comunidad Autónoma del País Vasco (CAPV), resulta de interés conocer el modelo que contempla el Sistema Vasco de Servicios Sociales, siendo pertinente conocer qué dice la Ley de Servicios Sociales del País Vasco de 2008 al respecto.

Así, si se analizan los principios y el modelo que contempla esta ley, se constata que en la Comunidad Autónoma del País Vasco se pretende avanzar hacia un modelo de atención centrado en la persona. En el artículo 7, la ley indica expresamente "la atención personalizada e integral”, y en el artículo 8, referido al modelo de atención y de intervención, destaca el enfoque comunitario y de proximidad en la atención. Este modelo, a pesar de haber estado especialmente vinculado al ámbito sociosanitario y a la atención de personas mayores y de personas con diversidad funcional, está actualmente presente no solo en la ley de servicios sociales analizada, sino también en los servicios sociales de la Comunidad Autónoma del País Vasco.

Sin intención de profundizar en el modelo ${ }^{8}$, a continuación se señalan algunas ideas que ofrece este enfoque teórico a la praxis profesional y que sirven de orientación para la resolución de supuestos prácticos. En este sentido, el modelo parte de la personalización e individualización de la atención y pretende favorecer el papel activo y protagonista de las personas atendidas, potenciando su autodeterminación, autonomía y motivación al cambio. Todo ello desde una relación horizontal con la persona, acompañando, apoyando y orientando. Para ello, es necesario trabajar a partir de fortalezas

información excepcionales para profundizar sobre el sistema de servicios sociales.

${ }^{8}$ Una aportación interesante sobre el modelo centrado en la persona la realiza Pilar Rodríguez (2013). 
y capacidades, y no tanto desde las carencias y debilidades. Junto a los recursos sociales, se deben potenciar los recursos personales, favoreciendo la participación activa y la toma de decisiones en todo el proceso. Además, la intervención debe ser integral y coordinada.

Este modelo ha tenido un importante impacto en el desarrollo del trabajo social, ya que aporta una filosofía de intervención muy acorde con los pilares básicos de la disciplina. Viscarret (2007) encuadra este modelo en el denominado modelo humanistaexistencialista que, a su vez, nos remite a Rogers con el enfoque no directivo centrado en la persona, y que aboga por una visión integradora y holística de la persona.

Para concluir, cabe destacar que el modelo teórico debe ser coherente con los principios y valores del trabajo social. Es imprescindible la consideración de la perspectiva ética de la intervención social, a partir de los principios éticos del trabajo social, aprobados por la Federación Internacional de Trabajadores/as Sociales (FITS, 2018) y el Código Deontológico (Colegios Oficiales de Trabajo Social, 2012), ya que establecen los principios ético-deontológicos y los criterios de actuación profesional.

\subsection{Proceso metodológico}

El método científico, en cuanto conjunto de procesos sistemáticos, es el modo de proceder propio de las ciencias y disciplinas científicas. Siguiendo el proceder del método científico se observa la siguiente secuencia: detectar-analizar-interpretargeneralizar-predecir-explicar-revisar, lo que conlleva un trabajo riguroso, con fundamento científico.

En trabajo social el método se estructura a través de cinco fases o etapas, bien conocidas por los y las profesionales, y está orientado hacia un doble fin: la construcción de conocimientos y la organización de una acción reflexiva, combinado así conocimientointervención y acción-reflexión.

A lo largo del tiempo y en función de los autores y las autoras, tanto la estructura de las fases del método como su denominación ha sido diversa, tal como se observa en el Cuadro 2. Ello no debe ser una fuente de confusión, ya que el contenido es el mismo.

Por tanto, el proceso metodológico en trabajo social ofrece una estructura secuencial. Está configurado por etapas interdependientes, que forman parte de un todo, flexibles en su aplicación. Debe ser
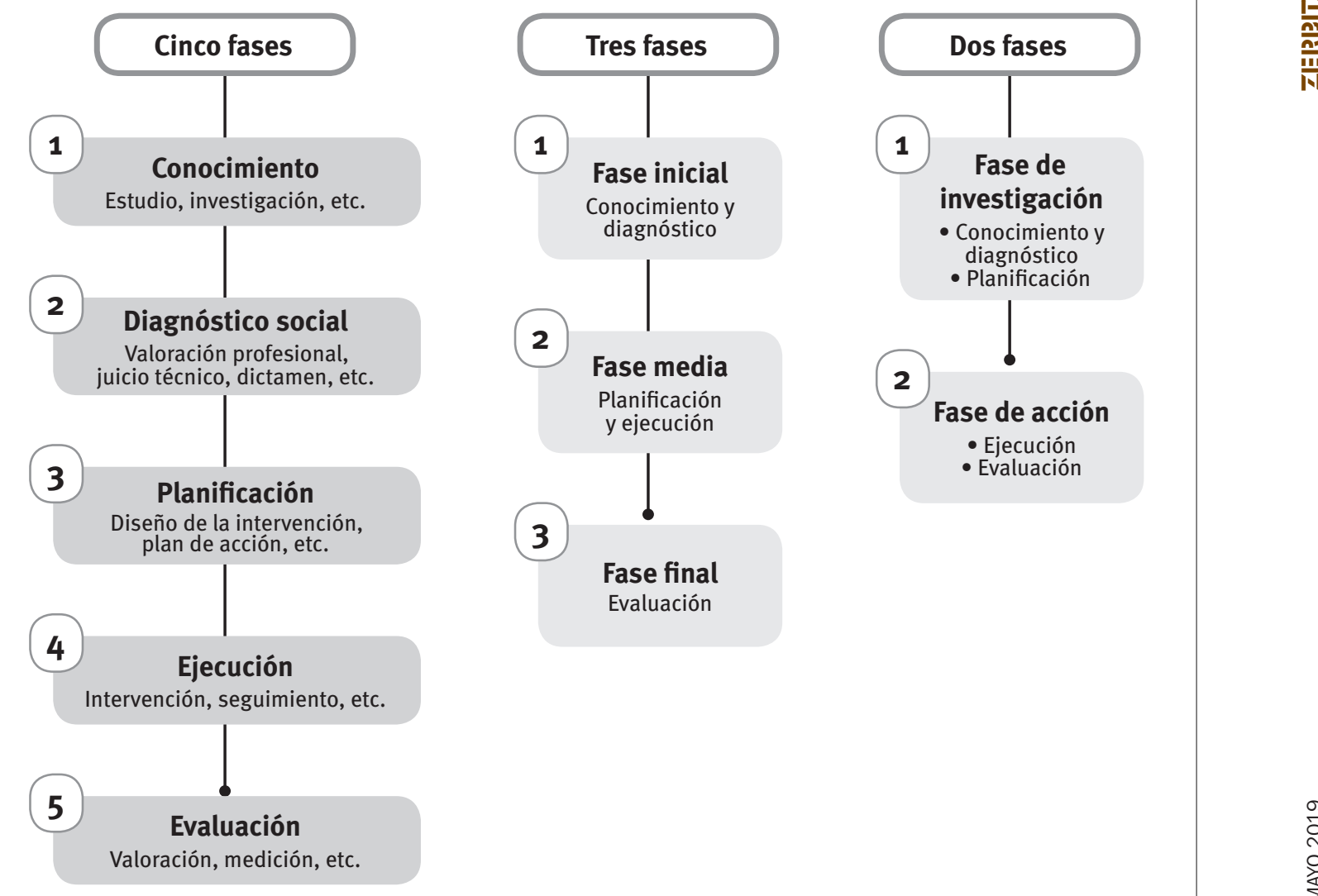

Fuente: Elaboración propia. 
entendido como un proceso circular, en espiral, situando en el centro de la intervención la demanda, que debe ser comprendida en su contexto. El método responde a criterios de globalidad, ofreciendo una perspectiva totalizadora y multidimensional, sin fragmentación? 9

\section{Cuadro 3. Proceso metodológico en trabajo social social}

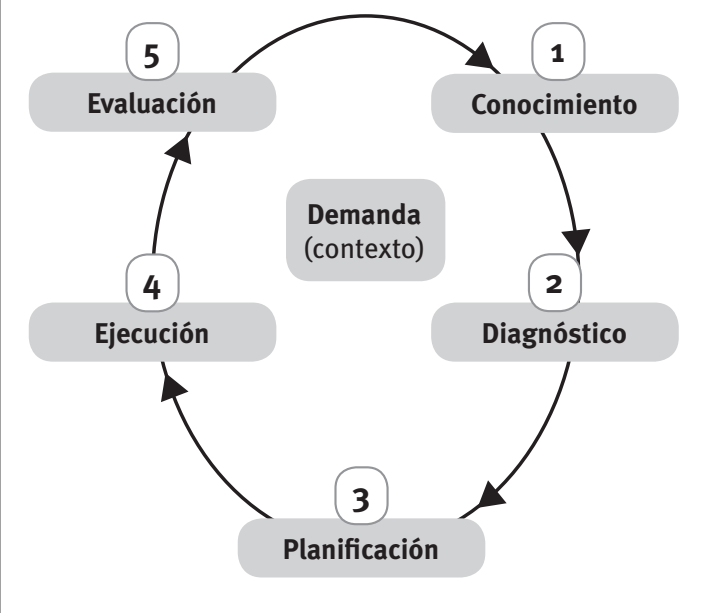

Fuente: Elaboración propia.
En el contexto de la Comunidad Autónoma del País Vasco, la Ley 12/2008 de Servicios Sociales en su artículo 19 hace referencia expresa al procedimiento básico de intervención, identificándose con el proceso metodológico descrito ${ }^{10}$.

\section{Diseño para la resolución de supuestos prácticos}

El manual de Francisco García (2001) ha sido un referente en la resolución de supuestos prácticos en trabajo social. Las publicaciones en torno a este tema son escasas y prácticamente en todas ellas se menciona a este autor, retomando sus aportaciones.

El diseño que se presenta retoma algunos de los elementos clave trabajados por este autor. Además, incorpora el modelo teórico junto al método, conjugando ambos y entendiendo el proceso metodológico como fases conexionadas. Esta conexión se expresa a través de elementos clave de cada etapa: información, valoración, estrategia, acciones y reformulación.

Asimismo, puesto que se trata de un supuesto práctico, a diferencia de la intervención profesional propiamente dicha, solo se podrá planificar la intervención y, por tanto, no es posible ejecutarla, ni evaluarla. Por ello, tal como se indica en el Cuadro 4, la fase de planificación, además del diseño de la intervención, incluirá el diseño de la fase de ejecución y de evaluación.

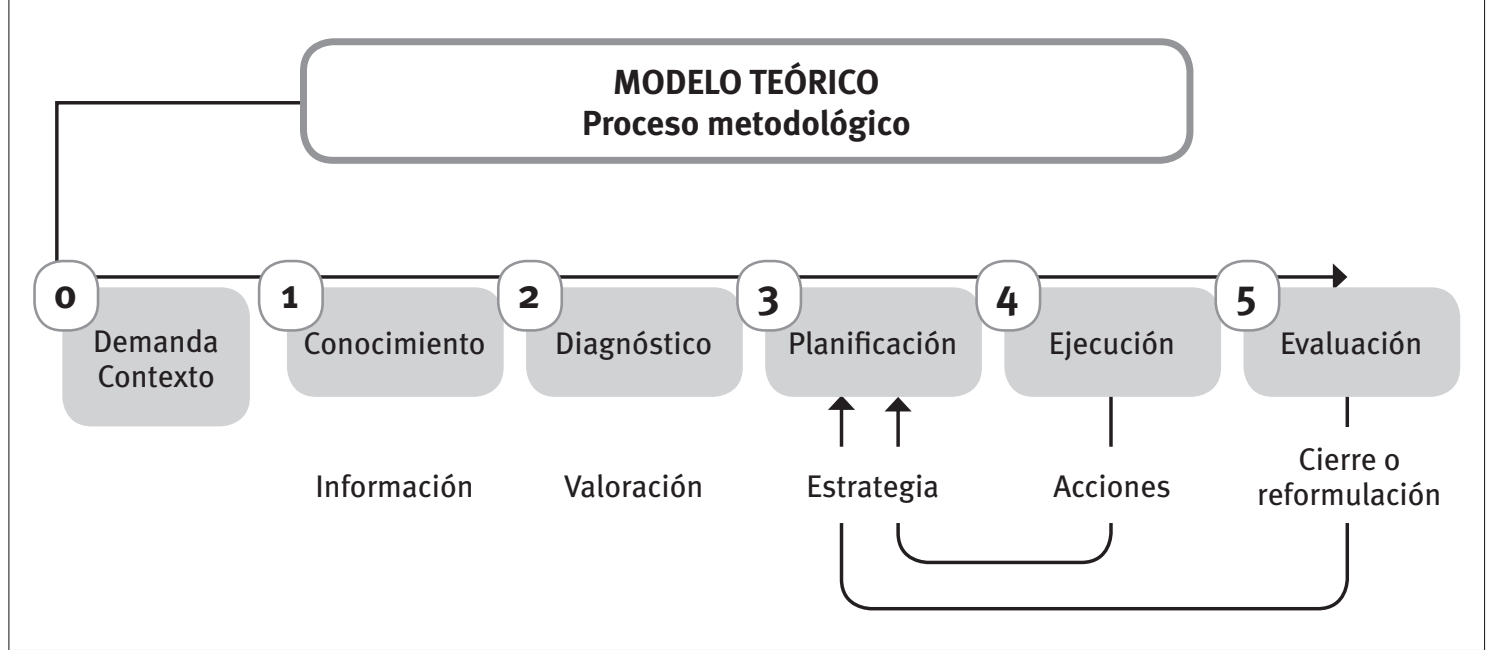

Fuente: Elaboración propia.

${ }^{10}$ El Departamento de Empleo y Asuntos Sociales del Gobierno Vasco (2012), en sintonía con el mencionado artículo 19 de la Ley $12 / 2008$, publicó un informe sobre la elaboración de un proceso de intervención en servicios sociales desde una perspectiva centrada en la persona. El informe plantea cinco fases, asimilables a las del método de trabajo social: recepción, valoración social, diagnóstico, plan de atención personalizada, seguimiento y evaluación. 
Este diseño ofrece una guía y unas pautas para el abordaje de supuestos prácticos. No obstante, cada alumno/a o profesional puede plantear un desarrollo diferente, ya que un mismo enunciado de supuesto puede tener distintas resoluciones y todas ellas ser adecuadas y pertinentes.

A continuación, se desarrollan las diferentes etapas y elementos que forman parte de este diseño, no perdiendo de vista que todo el proceso metodológico debe estar orientado por los principios y estrategias de acción del modelo teórico.

\section{o. Demanda}

La demanda constituye el punto de partida del proceso de intervención profesional y, por ende, de la resolución de supuestos prácticos. Así, se procederá a su definición y contextualización (institucional, profesional y legislativa), realizando una referencia expresa al modelo teórico.

\section{o.1. La definición de la demanda: quién la presenta, grado de concreción y contenido}

La demanda es la primera información que tiene el/ la profesional sobre la situación de necesidad en sí y sobre el nivel de conciencia que se tiene de ella. La exploración y definición de la demanda requiere precisar las siguientes cuestiones:

- Quién presenta la demanda. La demanda puede ser directa (persona/s afectada/s), indirecta (terceras personas: familiares, vecinos/as, etc.), derivada (profesionales de otros servicios, instituciones, etc.) o de oficio (ante situaciones de riesgo).

- Grado de concreción de la demanda. La demanda puede ser explicita (se identifica con la solicitud), inespecífica (con contenido poco claro) o implícita (no expresada).

- El contenido de la demanda. La demanda está relacionada con dificultades, necesidades y/o problemas sociales, mostrando carencias, debilidades, conflictos y amenazas. No obstante, se deben identificar también las fortalezas potenciales y oportunidades existentes.

Es necesario tener en cuenta la complejidad de la demanda, y con ello valorar el tipo de intervención: urgente, ordinaria o puntual. Asimismo, se tendrá en cuenta si se trata o no de un caso nuevo en el servicio, ya que implica diferencias en la información disponible.

\subsection{La demanda en su contexto: institucional, profesional y legislativo}

La demanda debe enmarcarse en el contexto en que se da la situación, su definición permite valorar las posibilidades, así como las limitaciones de la intervención, determinando en algunos casos las competencias profesionales. Deberá explicitarse el contexto institucional, profesional y legislativo.

- Se concreta el contexto institucional, el ámbito de intervención, así como la institución o entidad social desde la que se realiza la intervención profesional, especificando el servicio y ubicación geográfica.

- En cuanto al contexto profesional, se debe hacer referencia a los y las profesionales que intervienen, concretando profesional/es de trabajo social y otros perfiles, destacando la importancia del trabajo interdisciplinar y en equipo. Si es posible se concretará también la atribución de competencias y funciones profesionales. Se hará mención al código deontológico como marco para la regulación de los principios éticos y criterios de actuación.

- El contexto legislativo hace referencia a aquellos aspectos normativos que fundamentan la propuesta de intervención. Se hará explicita la legislación de referencia, teniendo en cuenta la legislación general y la específica vinculada al colectivo y/o a la situación-problema que se va a abordar. Si existen, se mencionarán también planes o programas institucionales relacionados con el contenido que se plantea.

En el encuadre de un supuesto práctico, además de los tres elementos señalados, también es pertinente incorporar una breve referencia teórica relacionada con el tipo de situación social planteada o, en su caso, la población a quien se dirige: exclusión social, dependencia, desprotección, etc.

\subsection{El modelo teórico de referencia: principios y criterios de intervención}

La intervención profesional y su diseño deben estar sustentados en modelos teóricos referenciales que fundamenten la práctica profesional y garanticen su efectividad. Será necesario destacar los principios fundamentales y los criterios de actuación, los cuales deben reflejarse en el diseño: en los objetivos propuestos, en las estrategias planteadas y en general en la filosofía que guía la propuesta de acción.

En la Comunidad Autónoma del País Vasco se propone el modelo de atención centrado en la persona, tal como recoge la Ley 12/2008 de Servicios Sociales. Respecto a este modelo, anotamos algunas de las ideas clave que orientan la intervención, como la importancia de partir de la demanda planteada por la persona; la persona es la primera fuente para obtener información; se deben valorar las capacidades y fortalezas, así como las necesidades de apoyo y los recursos informales y formales; el diagnostico debe ser compartido; el plan de intervención debe ser acordado, consensuando 
actividades, responsabilidades y compromisos, que se reflejen en un documento firmado; la intervención debe ser integral y requiere trabajo en red, una respuesta conjunta y coordinada de las diferentes administraciones y sistemas; se definen indicadores para el seguimiento y la evaluación de forma conjunta.

\section{Conocimiento}

La fase de conocimiento recoge la información necesaria para la compresión y valoración inicial de la situación. Se parte de la información disponible en el supuesto, estructurándola por áreas de necesidad (no olvidando las fortalezas) y se identifica la información no disponible y necesaria, indicando fuentes de información, técnicas de recogida de datos y de documentación.

Esta fase tiene como objetivo el conocimiento de la persona-familia y de la situación, sin olvidar su entorno, así como el contexto con todas sus interrelaciones. En todo caso, se recogerá solo aquella información que se considere necesaria para la intervención, con el objetivo de clarificar la demanda y detectar las áreas de necesidad. La entrevista, entendida como un diálogo en colaboración con la persona, permite la comprensión de la situación y la elaboración de la demanda.

\subsection{Información disponible en el supuesto: estructuración por áreas de necesidad y su registro}

Se trata de elaborar la demanda partiendo de la información que ofrece el enunciado del supuesto (la información con la que se cuenta), estructurándola por áreas de necesidad. La información se acompaña del registro en instrumentos técnicos como: genograma, ecomapa, mapa de relaciones, etc.

\subsection{Información no disponible y necesaria}

Identificar por áreas de necesidad: qué información, fuentes y técnicas de recogida y registro de información se prevén. Puesto que la información es incompleta y no es posible recoger la información necesaria para el conocimiento y comprensión de la situación, será necesario el diseño de esta recogida de información, para lo que se concretará:

- La información no disponible y necesaria para la resolución del supuesto práctico, organizada por áreas de necesidad, siempre en función del nivel de intervención.

- Las fuentes de información necesarias. Directas o indirectas: la propia persona (grupo o comunidad) o familiares, o personas próximas, profesionales o documentos (expedientes, informes, memorias, etc.).

- Las técnicas de recogida de información, como entrevistas, entrevistas colaterales, visitas a domicilio, observación, análisis de documentos, encuestas, grupos de discusión, entrevista grupal, etc.

- Las técnicas de documentación y de registro, como ficha e historia social, informe social, hoja registro de entrevista, hoja de visita a domicilio, cuestionarios, etc.

Por tanto, un elemento esencial de partida en la resolución de supuestos es la definición de las áreas de necesidad, ya que proporciona la conexión y coherencia necesaria para todo su desarrollo. Teniendo en cuenta el carácter explorativo del diseño de resolución de supuestos prácticos, a continuación se plantea una propuesta de posibles áreas de necesidad y consecuentemente áreas de intervención, contemplando tanto la dimensión individual-familiar, como la dimensión colectiva, y teniendo presente la importancia de partir de la demanda presentada.

Tabla 1. Áreas de necesidad por ámbitos

\begin{tabular}{|c|c|}
\hline Ámbitos & Áreas de necesidad \\
\hline Residencial & $\begin{array}{l}\text { - Situación residencial (empadronamiento) } \\
\text { - Situación jurídico-administrativa (situación } \\
\text { legal) }\end{array}$ \\
\hline $\begin{array}{l}\text { Económico- } \\
\text { laboral }\end{array}$ & $\begin{array}{l}\text { - Situación económica: ingresos y gastos } \\
\text { - Situación ocupacional-laboral }\end{array}$ \\
\hline Vivienda & - Situación de alojamiento y de vivienda \\
\hline Salud & $\begin{array}{l}\text { - Situación de la salud } \\
\text { - Situación de discapacidad e incapacidad } \\
\text { laboral } \\
\text { - Dependencia }\end{array}$ \\
\hline Educación & $\begin{array}{l}\text { - Educación; situaciones menores } \\
\text { - Formación-información-capacitación }\end{array}$ \\
\hline Personal & $\begin{array}{l}\text { - Actitud, vivencia y expectativas } \\
\text { - Competencias-habilidades sociales } \\
\text { - Usos de los sistemas de protección }\end{array}$ \\
\hline Convivencial & $\begin{array}{l}\text { - Situación relacional convivencial, personal, } \\
\text { familiar } \\
\text { - Vínculos afectivos y recepción de apoyo social }\end{array}$ \\
\hline Social & $\begin{array}{l}\text { - Relaciones convivenciales en otros contextos } \\
\text { - Aceptación social y convivencia cotidiana } \\
\text { comunitaria }\end{array}$ \\
\hline
\end{tabular}

Fuente: Elaboración propia a partir del Decreto 353/2013.

\section{Diagnóstico social}

A partir de la información recopilada, su análisis e interpretación, la fase de valoración profesional permite la construcción de hipótesis, el establecimiento de prioridades y la elaboración de un pronóstico, de cara a la comprensión de la situación y al establecimiento de estrategias de intervención.

Se trata de una etapa reflexiva, analítica y valorativa, donde se realiza el análisis de los datos sistematizados en la fase anterior y trata de aportar los elementos fundamentales y suficientes que expliquen una realidad determinada para programar una acción en base a la jerarquización de las problemáticas detectadas. No debemos olvidar que diagnosticar no supone tipificar o categorizar personas, sino valorar situaciones, necesidades 0 
problemáticas, teniendo siempre como principios generales referentes la individualización, la personalización y la participación. En este sentido, es importante la construcción de un diagnóstico compartido entre el/la profesional y la/s persona/s protagonista/s de la intervención.

En la Comunidad Autónoma del País Vasco, para la realización de diagnósticos sociales se cuenta con diferentes herramientas de apoyo en función de la contingencia concreta ${ }^{11}$.

\subsection{Análisis y valoración de la información}

Se parte de la información sistematizada en la fase de conocimiento (la información disponible en el enunciado). Se trata de definir y valorar la situación, analizando los aspectos más significativos, factores causales y efectos producidos, identificando las fortalezas y las debilidades.

El objetivo es doble, por un lado, detectar las áreas de necesidad, que se estructurarán en función de los ámbitos o dimensiones y, por otro, valorar las posibilidades de cambio y las oportunidades de mejora. Para ello es necesario identificar:

- Puntos débiles: necesidades, problemas, situaciones de conflicto, factores causales, factores de riesgo o condicionantes (resistencias, amenazas), dificultades para la intervención, etc.

- Puntos fuertes: capacidades, potencialidades, fortalezas, factores de protección (vínculos y apoyos), factores facilitadores (intereses, motivaciones), etc.

\subsection{Formulación de hipótesis}

A partir del análisis de los factores causales y condicionantes, es necesario realizar conjeturas sobre la situación y sobre las posibles respuestas. Estas hipótesis se deben contrastar y reconstruir con las personas atendidas, lo que permite analizar las posibles causas y efectos que originan, mantienen o agravan la situación, así como valorar posibles líneas de intervención.

Esta definición permite determinar las prioridades de intervención si fuera necesario. Los criterios generales para la determinación de la prioridad de la intervención son: la gravedad, la urgencia, la vivencia, los recursos personales y sociales disponibles, la efectividad, la incidencia y el consenso.

${ }^{11}$ Instrumento de diagnóstico social (Decreto 353/2013), en el anexo II se establece una clasificación entre diagnóstico inicial y diagnóstico en profundidad; Instrumento de valoración de la exclusión social (Decreto 385/2013); Instrumento de valoración de la dependencia (Ley 39/2006 y Decretos Forales); Instrumento de valoración de la desprotección (Decreto 152/2017).

\subsection{Elaboración del pronóstico}

Se trata de una predicción o proyección de futuro en el desarrollo de los acontecimientos, en el caso de no intervenir y en el caso de realizar determinadas intervenciones. Un pronóstico será favorable si se plantea mejora, desarrollo, etc. y será desfavorable si es necesaria la intervención para que no empeore. Compartir el pronóstico con las personas protagonistas supone la toma de conciencia de la situación y una motivación al cambio.

El pronóstico está asociado al problema en sí, a la cronicidad, a la conciencia del problema, a la motivación al cambio, y a los recursos y competencias personales, así como a las fuentes de apoyo social y al seguimiento de orientaciones y prescripciones profesionales.

\subsection{Valoración profesional}

Se trata de formular una valoración técnica o dictamen profesional consensuado, a modo de conclusión diagnóstica, base para la toma de decisiones compartidas en el proceso de planificación.

Esta valoración diagnóstica incluirá la definición de la situación, delimitando y definiendo las áreas de necesidad prioritarias, describiendo la interrelación entre ellas y destacando las debilidades y dificultades que agravan la situación, así como las potencialidades y los aspectos que favorecen la intervención, refiriendo si el pronóstico de la situación requiere la intervención y con ello el diseño de un plan de intervención.

\section{Planificación}

Fase de toma de decisiones con el fin de generar cambios deseables, de mejora, por medio de la articulación de objetivos, acciones, técnicas y recursos. En la resolución de supuestos prácticos, esta fase contempla, además del diseño de la intervención, el diseño del seguimiento y de la evaluación.

En función del nivel de atención y/o institución, esta fase puede adoptar distintas denominaciones, como plan de intervención, plan de trabajo, plan de atención personalizada (PAP) para la atención primaria y programa individual de atención (PIA) en atención secundaria del Sistema Vasco de Servicios Sociales. Dependiendo del contexto institucional en el que se encuadre el supuesto se optará por una u otra opción.

La planificación es un proceso participativo ${ }^{12}$, por lo que la propuesta inicial del plan se elaborará por el/ la profesional de referencia, pero será acordada con

${ }^{12}$ Algunas cuestiones sobre las que es necesario trabajar con la/s persona/s afectada/s son: cuál es la situación más grave y cuá la más urgente; cuáles preocupan más a las personas; cómo podría 


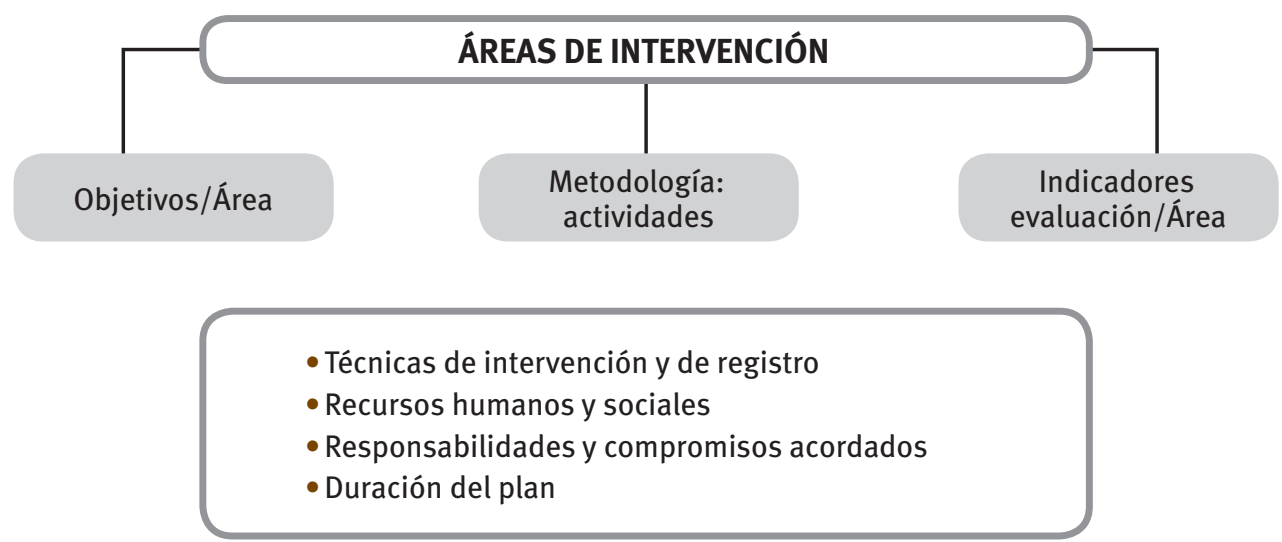

Fuente: Elaboración propia.

la/s persona/s implicada/s, tratando de llegar a una planificación compartida. Es decir, se trata de una tarea consensuada con las personas, de modo que se garantice la personalización y la autodeterminación. La etapa de planificación parte de la valoración profesional realizada en la fase de diagnóstico social y pretende el diseño de estrategias de intervención sobre las áreas de necesidad definidas, que requiere la toma de decisiones sobre algunas cuestiones que permiten organizar la intervención. Con el objetivo de garantizar la coherencia interna, se propone estructurar la información en esta fase de diseño del modo que se muestra en el Cuadro 5.

\section{1. Áreas de intervención}

El diseño de la estrategia de acción requiere concretar las áreas de necesidad sobre las que se propone intervenir. A través del diagnóstico se ha realizado la definición de las áreas de necesidad prioritarias en la intervención, en base a criterios como la gravedad, la urgencia, la vivencia, etc., por lo que en esta etapa de planificación se parte de la valoración de las áreas sobre las que es necesario intervenir definidas en la fase anterior, diseñando estrategias para cada una de ellas.

\subsection{Objetivos por áreas de intervención}

Se trata de definir la finalidad de la estrategia de intervención profesional para cada área de necesidad. Los objetivos reflejan los resultados que se desean conseguir, los propósitos, expresan qué se pretende lograr. Se formulan mediante un verbo en

resolverse la situación; cómo afrontar las amenazas; qué recursos internos y externos pueden activarse y cuáles son los más apropiados; qué tipo de acciones y estrategias pueden llevarse a cabo; cuáles serían más eficaces; cuáles serían más factibles y cuáles más satisfactorias, etc. infinitivo y responden a las preguntas "para qué se interviene" y "qué queremos conseguir".

Los objetivos pueden definirse como generales, específicos y operativos, según el nivel de concreción de la estrategia. En el caso de la resolución de supuestos prácticos, dado que es el nivel más concreto, se deben formular objetivos operativos o metas, evaluables y medibles a través de indicadores en la evaluación del proceso. Esta formulación de objetivos debe realizarse con la implicación de las personas, proponiendo la modificación y/o mejora de aspectos vinculados a las áreas de necesidad.

\subsection{Metodología: actividades y técnicas}

La planificación permite organizar y ordenar las acciones, "lo que se va a hacer" para lograr los objetivos marcados. Responde a las preguntas "qué se va a hacer" y "cómo se hará”, por lo que requiere la concreción de:

- Las acciones que ayudaran a conseguir los objetivos formulados. Las acciones deben formularse mediante sustantivos. Se explorarán las diferentes alternativas de intervención, contrastándolas con las personas implicadas y se decidirá qué actividades y tareas se propone desarrollar para la consecución de los objetivos previstos (las tareas son las unidades mínimas de concreción en un proyecto). Las actividades reflejan la atención técnica, por lo que estarán relacionadas con las funciones profesionales ${ }^{13}$.

${ }^{13}$ En el Código Deontológico (Colegios Oficiales de Trabajo Social, 2012) se enumeran las funciones profesionales. Algunos ejemplos de actividades: información, asesoramiento, orientación; acogida, recogida de información y de documentación; investigación y valoración de la situación; apoyo profesional y atención directa; gestión y tramitación de recursos sociales; coordinación interprofesional e interinstitucional; seguimiento y evaluación, derivación a otros recursos; apoyo a la unidad familiar; fortalecimiento de redes de apoyo 
- Las técnicas e instrumentos que permiten llevar a cabo las actividades y también registrarlas ${ }^{14}$. El criterio básico en la elección de técnicas debe ser el mayor grado de participación de las personas protagonistas.

\subsection{Recursos}

La planificación requiere la elección de los recursos a aplicar, respondiendo a la pregunta "con qué contamos". Pueden ser recursos humanos, sociales, técnicos-materiales y económicos. En la resolución de supuestos prácticos, se hará referencia en especial a los recursos humanos y sociales. Se trata de concretar con quién y con qué contamos.

- Recursos humanos: las personas implicadas en primer lugar, profesionales de trabajo social, como recurso en sí mismo, y otros profesionales, familiares, personal de apoyo, voluntariado, etc.

- Recursos sociales e institucionales: servicios y prestaciones ${ }^{15}$.

\subsection{Responsabilidades y compromisos}

En el diseño de la intervención, vinculado a las actividades propuestas, se especificarán las responsabilidades y compromisos de las personas implicadas (trabajador/a social y persona/s implicada/s). Responde a la pregunta ¿quiénes? Se trata de un proceso acordado, en el que los/as profesionales tienen responsabilidades y las personas protagonistas adquieren compromisos.

\subsection{Duración}

Se trata de responder a la pregunta “cuándo se desarrollará la intervención" y con ello, establecer plazos y un calendario de las actividades a desarrollar. Aunque no existe ninguna indicación temporal generalizable, la planificación de la intervención suele tener una duración de entre seis meses y un año. Esta indicación temporal

social; apoyo y desarrollo de grupos, así como asistencia técnica a los grupos, supervisión; mediación; prevención; etc.

${ }^{14}$ En el manual coordinado por Cinta Guinot (2008) se recogen las principales técnicas de intervención profesional en trabajo social y las técnicas de registro y documentales. Algunos ejemplos: entrevista inicial; entrevista de seguimiento; visita domiciliaria; observación; reuniones; ficha social; historia social; expedientes; informe social; genograma, ecomapa, mapa de relaciones familiares y mapa de redes; hoja de registro de entrevista, de seguimiento, de visita domiciliaria, de derivación; etc.

${ }^{15}$ Para la definición de los recursos necesarios es imprescindible el conocimiento actualizado de la institución en la que se desarrolla y contextualiza el supuesto, así como el conocimiento de los servicios y prestaciones de otras instituciones y entidades. En el contexto de la Comunidad Autónoma del País Vasco, es indispensable la referencia al Decreto de Cartera de Prestaciones y Servicios (185/2015), destacando el Servicio de información, valoración, diagnóstico y orientación, que hace referencia expresa a la intervención profesional del trabajo social. sería suficiente en la resolución de supuestos. No obstante, las actividades pueden acompañarse de un cronograma o un diagrama de Gantt que refleje de manera detallada cuándo se realizará cada una de las actividades.

\subsection{Diseño del seguimiento}

La ejecución supone la puesta en marcha de las acciones diseñadas en los plazos establecidos. La ejecución de las acciones requiere la organización, coordinación, dirección y supervisión de todo el proceso. Se realizará de forma flexible, adaptándose a las diferentes situaciones y acontecimientos no previstos en la planificación, sin perder de vista los objetivos fijados pero introduciendo las modificaciones necesarias. En su desarrollo se tendrán en cuenta los principios y los criterios de actuación del modelo teórico de referencia que guían la intervención. En esta fase es esencial activar la participación, colaboración e implicación de la/s persona/s, siendo su finalidad el desarrollo de potencialidades y la promoción de los recursos personales y sociales, provocando cambios positivos.

Por todo ello, el seguimiento de las acciones es esencial y debe quedar registrado de modo que facilite la evaluación. Los registros documentales suponen la sistematización de las prácticas o intervenciones realizadas, lo cual contribuirá a la consecución de una evaluación eficaz.

\subsection{Evaluación}

Se trata de una etapa reflexiva, cuyo objetivo es la valoración crítica de las intervenciones realizadas y del propio diseño de la intervención. Aunque no tome forma concreta hasta finalizar el proceso, supone un proceso continuo. Pero ¿qué evaluar y cómo? Se pueden evaluar los resultados (objetivos), la cobertura, la eficacia y eficiencia, el impacto, incluyendo las consecuencias no previstas, etc., pero también se puede evaluar el propio proceso (metodología), las actividades y las técnicas elegidas, la idoneidad de las medidas tomadas, los recursos aplicados, el grado de participación de la persona, el propio funcionamiento, etc.

El indicador de evaluación es un instrumento para la realización del seguimiento y de la evaluación. Desde el punto de vista metodológico los indicadores constituyen el máximo grado de operacionalización de las variables, facilitando una información concisa. Los indicadores pueden tener un carácter cuantitativo o cualitativo, marcando así el tipo de evaluación. A través de la evaluación se decidirá si es necesario reformular el plan modificando las estrategias de acción o si la intervención se cierra en el caso de que se hayan conseguido los objetivos previstos. En la resolución de supuestos se realizará un diseño de la evaluación a través principalmente de la definición de indicadores de evaluación de resultados, 


\section{DISEÑO PARA LA RESOLUCIÓN DE SUPUESTOS PRÁCTICOS EN TRABAJO SOCIAL}

\section{o. Demanda}

La demanda constituye el punto de partida del proceso de intervención profesional, y por ende, de la resolución de supuestos prácticos. Así, se procederá a su definición y contextualización (institucional, profesional y legislativa), realizando una referencia expresa al modelo teórico.

- La definición de la demanda

- La demanda en su contexto

- El modelo teórico de referencia

\section{Conocimiento}

Fase que recoge la información necesaria para la compresión y valoración inicial de la situación. Se parte de la información disponible en el supuesto, estructurándola por áreas de necesidad (debilidades y fortalezas) y se identifica la información no disponible y necesaria, indicando fuentes de información, técnicas de recogida de datos y de documentación.

1.1. Información disponible en el supuesto

1.2. Información no disponible y necesaria

\section{Diagnóstico social}

Fase de valoración profesional que, a partir de la información recopilada, su análisis e interpretación, permite la construcción de hipótesis, el establecimiento de prioridades y la elaboración de un pronóstico, de cara a la comprensión de la situación y al establecimiento de estrategias de intervención.

2.1. Análisis y valoración de la información

2.2. Formulación de hipótesis

2.3. Elaboración del pronóstico

2.4. Valoración profesional

\section{Planificación}

Fase de toma de decisiones vinculadas a estrategias de acción, con el fin de generar cambios deseables, por medio de la articulación de objetivos, acciones, técnicas y recursos. Esta fase contempla el diseño de la intervención, del seguimiento y de la evaluación.

3.1. Áreas de intervención (diagnóstico)

3.2. Objetivos por áreas de intervención

3.3. Metodología (actividades y técnicas)

3.4. Recursos

3.5. Responsabilidades y compromisos.

3.6. Duración

3.7. Seguimiento

3.8. Evaluación
¿Sobre qué?

¿Para qué?

¿Qué y cómo?

¿Con qué?

¿Quiénes?

¿Cuándo?

¿Cómo se realizará el seguimiento?

¿Qué indicadores de evaluación?

Fuente: Elaboración propia.

${ }^{16}$ Tomás Fernández y Laura Ponce de León (2018), ofrecen una reflexión teórica y aportan una selección de indicadores de evaluación de la intervención individual-familiar. A modo de ejemplo, se presentan algunos indicadores cualitativos: incremento de ingresos mensuales, cobertura de gastos de bienes básicos, de gastos de vivienda o extraordinarios; impago o endeudamiento cubierto; eliminado riesgo de embargo; mejora situación vivienda y de equipamiento; eliminación de barreras arquitectónicas, mejora de acceso a servicios básicos; implicación de personas usuarias; toma de conciencia de situación; modificación de actitudes; cumplimiento de compromisos; asistencia a actividades; grado de satisfacción; etc. Respecto a indicadores cuantitativos, algún ejemplo: número de entrevistas, visitas a domicilio, reuniones, recursos gestiones, informes sociales, formaciones realizadas, etc. 


\section{Decálogo para supuestos prácticos}

A modo de conclusión, se destacan algunas ideas clave para la resolución de supuestos prácticos, en especial en procesos de evaluación, tanto para alumnado como para profesionales.

- Recordar que un supuesto práctico es el diseño teórico de la intervención profesional, por lo que requiere conocimientos legislativos, institucionales-organizacionales, disciplinaresprofesionales, etc., actualizados.

- Aprovechar los saberes adquiridos de la experiencia profesional y hacer explícita la especificidad de trabajo social, en especial el enfoque globalizador del objeto disciplinar.

- Elegir el modelo teórico que guiará el diseño de la intervención y hacerlo evidente a lo largo de la resolución.

- Tener siempre presente el método básico de trabajo social, el proceso metodológico de la intervención profesional.
- Decidir un diseño para su resolución, la estructura-esquema que se aplicará a cualquier supuesto práctico, comenzando con la contextualización de la demanda.

- Analizar en profundidad el enunciado del supuesto, hasta llegar a una buena y completa comprensión, clarificando lo que se pide.

- Diseñar esquemáticamente la resolución antes de empezar a redactar, de manera que se garantice la coherencia interna, la lógica secuencial y argumental, sin contradicciones.

- Gestionar el tiempo adecuadamente para presentar la resolución completa, cuidando, además del contenido, la presentación, la redacción y el lenguaje técnico.

- Recordar que no hay una única resolución correcta; un mismo supuesto puede tener distintos diseños y todos ellos ser adecuados.

- Centrar, ordenar, estructurar las ideas y tener autoconfianza. 


\section{Enunciado}

A un servicio social de base del Ayuntamiento de Vitoria-Gasteiz acude Nora, con expediente abierto en el servicio. Nora, mujer de 35 años de origen marroquí, está casada con Mohamed, de 40 años, con quien tiene dos hijas, Hana y Anisa, de 12 y 8 años. Viven también con el padre de él, Amir, de 70 años y con problemas de movilidad. Residen en Vitoria-Gasteiz desde hace más de quince años. Nora no mantiene relaciones con su familia de origen.

Nora no trabaja fuera de casa, pero expresa su deseo de trabajar, aunque sea unas horas. Su pareja está en el paro desde hace cuatro años, anteriormente trabajó de temporero y en la construcción. El único ingreso del hogar es la pensión de Amir, por lo que no pueden afrontar la deuda contraída de tres meses por el impago de alquiler del piso. Anteriormente cobraron la Renta de Garantía de Ingresos (RGI), pero se les suspendió porque fueron a un viaje a su país de origen y estuvieron un mes.

Nora afirma que las relaciones con su pareja son conflictivas. Consta en el expediente un parte de la policía local del grupo de violencia familiar, informando que han realizado una intervención en el domicilio de Nora, por la denuncia de un vecino, quien manifestó que oía gritos e insultos entre personas adultas y lloros de niñas.

Ante esta situación, se solicita al trabajador o trabajadora social que diseñe la intervención con esta familia.

\section{Resolución del supuesto práctico}

\section{o. La demanda}

\section{La demanda: quién la presenta, grado de concreción y contenido}

Nora, de origen marroquí, casada y con dos hijas, acude al servicio social de base del Ayuntamiento de Vitoria-Gasteiz (con expediente abierto), exponiendo una demanda de ayuda económica: el pago de la deuda acumulada por el impago del alquiler de la vivienda de la unidad familiar. La demanda es directa y compleja, ya que la situación de necesidad económica parece estar originada por el desempleo de su marido y de ella. Además, Nora expresa una relación conflictiva con su pareja. En el expediente se recoge una intervención en el domicilio de la policía local del grupo de violencia familiar.
La demanda en su contexto: institucional, profesional y legislativo

El ámbito institucional en el que se ubica el supuesto es el Departamento de Políticas Sociales y Salud Pública del Ayuntamiento de Vitoria-Gasteiz, y más en concreto en un servicio social de base, enmarcado en el Servicio de Acción Comunitaria. Los servicios sociales de base son unidades organizativas ubicadas en los centros cívicos de la ciudad como primer punto de acceso al sistema de servicios sociales. Pretenden dar respuesta a los problemas y necesidades personales, familiares o sociales de la ciudadanía y favorecer su integración social y autonomía. Todo ello a través de prestaciones y servicios basados fundamentalmente en lo personal y relacional.

A pesar de no citarse expresamente en el supuesto, entendemos que el equipo profesional con el que cuenta el servicio social de base es un equipo interdisciplinar formado por una persona responsable del servicio, al menos un/a trabajador/a social, un/a psicólogo/a, un/a educador/a de calle y personal administrativo. En este supuesto, en un primer momento, se realizará la intervención por parte del trabajador o trabajadora social para posteriormente, y en función de la valoración inicial, ir decidiendo la idoneidad de incorporar a otros perfiles profesionales. En el caso de los y las trabajadoras/res sociales, el Código Deontológico de la Profesión (2012) recoge las funciones propias de este perfil profesional: información, investigación, prevención, asistencia, atención directa, promoción e inserción social, mediación, planificación, gerencia y dirección, evaluación, supervisión, docencia y coordinación.

El marco jurídico de referencia para los servicios sociales de atención primaria del Sistema Vasco de Servicios Sociales y para la situación planteada, se concreta fundamentalmente en:

- Ley $12 / 2008$ de Servicios Sociales.

- Decreto 64/2004 de Carta de Derechos y Obligaciones de las personas usuarias y profesionales de los servicios sociales.

- Decreto 185/2015 de Cartera de Prestaciones y Servicios del Sistema Vasco de Servicios Sociales.

- Decreto 353/2013 de Ficha Social y del instrumento de diagnóstico social del Sistema Vasco de Servicios Sociales.

- Ley $18 / 2008$ para la Garantía de Ingresos y para la Inclusión Social y sus modificaciones y su desarrollo normativo (especialmente el Decreto 4/2011 Prestación Complementaria Vivienda y Decreto 16/2017 de Ayudas de Emergencia Social).

\footnotetext{
${ }_{17}$ Agradecemos la colaboración de las y los trabajadores sociales con quienes se ha contrastado esta propuesta, casi un centenar de profesionales del Colegio Oficial de Trabajo Social de Álava, en el marco de los talleres sobre supuestos prácticos impartidos en 2018 y 2019.
} 
- Ordenanza reguladora del programa de Prestaciones Económicas Municipales 2018.

- Ley 3/2005 de Atención y Protección a la Infancia y la Adolescencia.

- Ley Orgánica 8/2015 de modificación del sistema de protección a la infancia y a la adolescencia.

- Decreto 152/2017 de actualización del Instrumento Balora.

- Ley 39/2006 de promoción de la autonomía personal y atención a las personas en situación de dependencia.

- Ley Orgánica 1/2004 de Medidas de Protección Integral contra la Violencia de Género.

- II Acuerdo interinstitucional para la mejora en la atención a mujeres víctimas de maltrato en el ámbito doméstico y de violencia sexual.

- Ley Orgánica 3/2018 de Protección de Datos Personales y garantía de los derechos digitales.

\section{El modelo teórico de referencia: principios y criterios de intervención}

Partiendo de los principios y el modelo de atención recogido en la Ley 12/2008 de Servicios Sociales para el Sistema Vasco de Servicios Sociales, el diseño de la intervención para este supuesto se sustenta en el modelo de atención centrado en la persona. Los principios fundamentales de este modelo son: autonomía, individualidad, independencia, integralidad, participación, inclusión social y continuidad en la atención. Respecto a los criterios de intervención, caben señalar los siguientes: diversidad y empoderamiento, personalización y flexibilidad, prevención y visibilización de las capacidades, globalidad, accesibilidad e interdisciplinariedad, proximidad y enfoque comunitario, coordinación y convergencia. Tanto los principios como los criterios de intervención guiarán el proceso de diseño de la intervención de este supuesto práctico.

\section{Conocimiento}

\section{Información disponible en el supuesto}

Los datos con los que contamos son los siguientes: Es una familia de origen marroquí, con residencia en Vitoria-Gasteiz desde hace más de quince años. La familia la componen cinco miembros: la pareja, dos hijas y el padre del hombre. El genograma sería el siguiente:

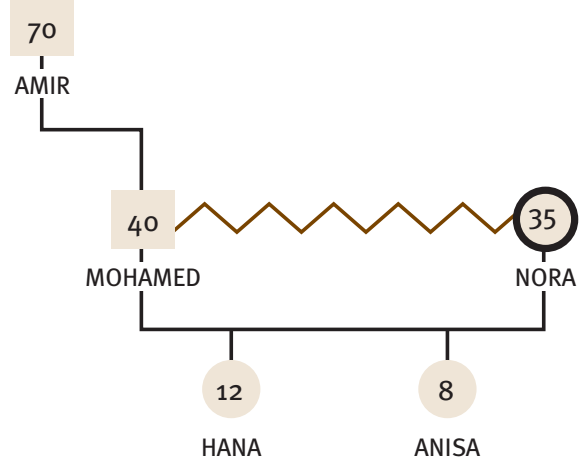

La información disponible, estructurada por áreas de necesidad, es la siguiente:

- Situación económica. El único ingreso familiar es la pensión de Amir. La familia tiene una deuda de tres meses por impago del alquiler de la vivienda familiar. Percibieron RGI, pero se suspendió por encontrarse fuera del país durante un mes.

- Situación laboral. Mohamed se encuentra en paro desde hace cuatro años, teniendo experiencia laboral anterior como temporero y en la construcción. Nora no trabaja fuera del hogar, aunque expresa estar motivada para hacerlo.

- Situación de vivienda. Residen en un piso de alquiler y no cuentan con recursos económicos para afrontar el alquiler de los últimos tres meses.

- Situación en relación con el apoyo familiar. Nora no mantiene relaciones con su familia de origen.

- Situación relacional-convivencial. Nora expresa que las relaciones con su pareja son conflictivas. Existe un parte del grupo de violencia familiar de la policía local donde constan gritos entre personas adultas y lloros de niñas.

\section{Información no disponible y necesaria}

Para un adecuado diagnóstico social es pertinente recoger información relativa a diferentes áreas:

- Económica: cuantía de la deuda contraída, cuantía del alquiler mensual, cuantía de la pensión de Amir, situación actual con relación a la RGI. Percepción de ayudas de otras instituciones 0 entidades.

- Laboral: cualificación profesional y vida laboral de Mohamed y Nora.

- Residencial: empadronamiento.

- Administrativa-jurídica: regularizada o no.

- Vivienda: existencia o no de contrato de alquiler y titularidad privada o pública, condiciones de habitabilidad, accesibilidad, etc.

- Relacional-convivencial: ampliar información sobre la relación conflictiva entre Nora y Mohamed, y cómo afecta al resto de miembros de la familia.

- Salud: estado de salud de Amir.

- Educación: situación escolar de las niñas.

- Actitud y vivencia: consciencia y vivencia de la situación, intención de participación activa en el abordaje y superación de las dificultades por parte de Nora y de Mohamed.

- Expectativas: cómo esperan que se les apoye desde el servicio social de atención primaria.

- Red de apoyo familiar: familia extensa, trayectoria familiar y motivos de la escasa relación con familia de origen de Nora.

- Redes sociales de apoyo: posibles redes de apoyo primarias (familia-no familia) y secundarias (comunitarias-institucionales). 
Para ampliar la información disponible, las fuentes de información que se proponen son: en primer lugar, fuentes directas, la propia persona demandante y su pareja. Paralelamente, también serán fuentes de información el expediente abierto y los/as profesionales implicados/as en el registro de la intervención policial. Posteriormente, a través de fuentes indirectas, se valorará la necesidadidoneidad, con el consentimiento de la persona, de coordinación con otros/as profesionales y/o sistemas de protección social con los que mantiene relación la familia (médico/a y enfermero/a de atención primaria, tutores/as del centro escolar, etc.).

Respecto a las técnicas de recogida de información, serán fundamentalmente las entrevistas sucesivas con Nora y Mohamed, por separado y conjuntas. Posteriormente se valorará la realización de visita a domicilio y la coordinación con otros/as profesionales. La información recogida se incorporará en el expediente, ficha social, registros de intervenciones, etc.

\section{Diagnóstico social}

\section{Análisis y valoración de la información}

A la luz de la información existente, cabe señalar tanto elementos limitadores como favorecedores de la intervención.

Las dificultades se sitúan en las siguientes áreas de necesidad prioritarias en función de la urgencia y la gravedad:

- Área económica: escasez de recursos (deudas y gastos básicos).

- Área convivencial: relación conflictiva de pareja.

- Área laboral: situación de desempleo de Nora y Mohamed.

- Área apoyo social: ausencia red de apoyo familiar de Nora.

Las potencialidades de la unidad familiar que cabría destacar:

- Área económica: ingresos escasos pero periódicos y garantizados.

- Área de vivienda: disponibilidad de vivienda.

- Área personal: la iniciativa de Nora de acudir al servicio, de compartir la relación conflictiva que mantiene con su pareja y el deseo de trabajar.

\section{Hipótesis}

Partiendo de la demanda realizada por Nora, encontramos una escasez de recursos económicos para hacer frente a las necesidades básicas (alimentación y alojamiento) que afecta a toda la unidad familiar en la que hay dos niñas y una persona mayor. Esta situación viene motivada por la pérdida de la RGI y fundamentalmente por la situación de desempleo tanto de Nora como de Mohamed.

Por otro lado, y a partir de la relación conflictiva de pareja expresada por Nora y la intervención policial del grupo de violencia familiar de la policía local, cabe formular la hipótesis de malos tratos de Mohamed hacia Nora. Además, la ausencia de red de apoyo familiar de Nora también puede ser un indicador de maltrato, provocando el aislamiento del entorno familiar. Dado que el vecino que realizó la denuncia manifestó oír gritos, insultos y lloros de niñas, es posible que, si se están produciendo malos tratos, estos estén afectando también a las menores y a la persona mayor de la unidad familiar, conduciendo a una situación de desprotección por exposición a la violencia.

\section{Pronóstico}

Se plantea una situación familiar que requiere la intervención de los servicios sociales de base de cara a la consecución de mejoras en el área económica, laboral, convivencial y de apoyo social, en primera instancia. La no intervención probablemente conduciría al agravamiento de la situación familiar, ya que existe riesgo de pérdida de vivienda por impagos, posibles malos tratos hacia la mujer y desprotección por exposición a la violencia de las menores.

\section{Valoración profesional}

Familia con dos niñas y una persona mayor con problemas de movilidad, presenta una situación económica insuficiente para hacer frente a gastos básicos de alimentación y alojamiento, provocada por la situación de desempleo de los dos progenitores y la no percepción de ayudas económicas. La situación se agrava por los indicios de malos tratos existentes de Mohamed hacia Nora, que pudieran estar provocando una situación de desprotección de las dos menores. El mantenimiento de esta situación en el tiempo plantea un pronóstico desfavorable, con riesgo de exclusión social. Por ello, es necesaria y pertinente la intervención profesional desde los servicios sociales de atención primaria de cara a implementar un plan de trabajo compartido que contribuya a la mejora de la situación.

Este diagnóstico inicial se le dará a conocer a Nora, y si es posible, a Mohamed, para poder trabajar conjuntamente y llegar a un diagnóstico compartido.

\section{Planificación}

Dado que nos encontramos en un servicio social de atención primaria, se realizará el diseño de un plan de atención personalizada (PAP). 
Partiendo del diagnóstico inicial realizado por el/ la profesional (pendiente de compartir y acordar con Nora y Mohamed), y considerando la demanda económica y la relación conflictiva expresada por
Nora, se plantea una atención integral a la familia que pretende prevenir situaciones de riesgo.

Para ello se presenta el siguiente diseño de la intervención, del seguimiento y de la evaluación:

\begin{tabular}{|c|c|c|}
\hline Objetivos & Metodología & Indicadores de evaluación \\
\hline $\begin{array}{l}\text { Valorar los indicios de } \\
\text { malos tratos en la pareja } \\
\text { e intervenir en el caso de } \\
\text { confirmarse. }\end{array}$ & $\begin{array}{l}\text { - Realización de entrevista con Nora y Mohamed; en primer lugar, } \\
\text { por separado y posteriormente conjunta. } \\
\text { - Coordinación con los/as profesionales que realizaron la } \\
\text { intervención policial en el domicilio. } \\
\text { - Incorporación del/a psicólogo/a del equipo en el supuesto de } \\
\text { caso confirmarse los indicios de violencia de género. } \\
\text { - Información sobre protocolos y servicios de atención a víctimas } \\
\text { de violencia de género. } \\
\text { - Derivación al servicio Hegoak para valoración y atención } \\
\text { psicosocial. } \\
\text { - Seguimiento del caso a través de coordinaciones con } \\
\text { profesionales que intervengan en el caso, entrevistas, etc. }\end{array}$ & $\begin{array}{l}\text { - Se conoce la existencia o no de } \\
\text { malos tratos en la pareja. } \\
\text { - En el caso de existir malos } \\
\text { tratos, se ha puesto en marcha } \\
\text { el proceso de intervención } \\
\text { pertinente. }\end{array}$ \\
\hline $\begin{array}{l}\text { Detectar e intervenir en } \\
\text { una posible situación de } \\
\text { desprotección de las dos } \\
\text { niñas. }\end{array}$ & $\begin{array}{l}\text { - Realización de visita domiciliaria. } \\
\text { - Coordinación con profesorado del centro escolar. } \\
\text { - Coordinación con médico/a de atención primaria. } \\
\text { - Incorporación de otros perfiles profesionales del equipo si } \\
\text { fuesen necesarios (psicólogo/a y/o educador/a de calle). } \\
\text { - Aplicación del instrumento BALORA para valorar la gravedad de } \\
\text { la situación de riesgo y desamparo, si se considera necesario. } \\
\text { - Derivación al Servicio de Infancia si del BALORA se concluye } \\
\text { desprotección moderada. }\end{array}$ & $\begin{array}{l}\text { - Se conoce la existencia o no de } \\
\text { situación de desprotección de las } \\
\text { dos niñas. } \\
\text { - En el caso de existir desprotección } \\
\text { moderada, se ha puesto en } \\
\text { marcha el proceso de intervención } \\
\text { pertinente (Derivación Servicio } \\
\text { Municipal de Infancia). }\end{array}$ \\
\hline \multicolumn{3}{|c|}{ ÁREA DE SALUD } \\
\hline Objetivos & Metodología & Indicadores de evaluación \\
\hline $\begin{array}{l}\text { Detectar posibles } \\
\text { necesidades de la persona } \\
\text { mayor derivadas de los } \\
\text { problemas de movilidad. }\end{array}$ & $\begin{array}{l}\text { - Valoración la autonomía y las habilidades para la vida diaria. } \\
\text { - Coordinación con médico/a y enfermero/a de atención } \\
\text { primaria. }\end{array}$ & $\begin{array}{l}\text { - Se conocen las necesidades } \\
\text { vinculadas al estado de salud } \\
\text { de Amir. } \\
\text { - Se conoce el nivel de autonomía. }\end{array}$ \\
\hline \multicolumn{3}{|c|}{ ÁREA LABORAL } \\
\hline Objetivos & Metodología & Indicadores de evaluación \\
\hline $\begin{array}{l}\text { Posibilitar la orientación } \\
\text { laboral y la cualificación } \\
\text { profesional de Nora y } \\
\text { Mohamed. }\end{array}$ & $\begin{array}{l}\text { - Derivación a servicios de orientación laboral para la confección } \\
\text { de itinerarios personalizados: Sartu, Lanbide, etc. } \\
\text { - Acompañamiento en la búsqueda de cursos de formación } \\
\text { adaptados a sus perfiles y adecuados a la realidad del mercado } \\
\text { de trabajo: Sartu, Lanbide, Cruz Roja, Cáritas, etc. }\end{array}$ & $\begin{array}{l}\text { - Nora y Mohamed han recibido } \\
\text { orientación laboral y han } \\
\text { elaborado los respectivos } \\
\text { itinerarios personalizados. } \\
\text { - Nora y Mohamed han iniciado } \\
\text { procesos de formación para } \\
\text { mejorar su empleabilidad o } \\
\text { han conseguido incorporarse al } \\
\text { mercado laboral. }\end{array}$ \\
\hline \multicolumn{3}{|c|}{ ÁREA DE APOYO SOCIAL } \\
\hline Objetivos & Metodología & Indicadores de evaluación \\
\hline $\begin{array}{l}\text { Fomentar redes de apoyo } \\
\text { social. }\end{array}$ & $\begin{array}{l}\text { - Fortalecimiento de redes de apoyo primarias con las que pueda } \\
\text { contar la familia. } \\
\text { - Información y acompañamiento para actividades dirigidas a } \\
\text { menores (ludotecas, etc.). } \\
\text { - Información y orientación para la incorporación en actividades } \\
\text { comunitarias para personas mayores (centros socioculturales } \\
\text { de mayores del barrio, etc.). }\end{array}$ & $\begin{array}{l}\text { - Cuentan con red de apoyo social } \\
\text { primario. } \\
\text { - Las niñas participan en alguna } \\
\text { actividad de tiempo libre. } \\
\text { - Amir participa en alguna actividad } \\
\text { dirigida a personas mayores. }\end{array}$ \\
\hline
\end{tabular}


De las acciones definidas en la metodología, se desprende la utilización de técnicas, de intervención y de documentación, como entrevistas, entrevistas colaterales, visitas a domicilio, ficha e historia social, registro de entrevistas, hojas de seguimiento, genograma, informe social, etc.

Con relación a los recursos, para desarrollar la estrategia de intervención diseñada serían necesarios los siguientes:

- Humanos: los miembros de la familia, trabajador/a social, y si fuese necesario psicólogo/a, educador/a de calle, médico/a de cabecera, enfermero/a, profesorado, etc.

- Institucionales (servicios y prestaciones): servicio de información, valoración, diagnóstico y orientación del servicio social de base, RGI, $\mathrm{PCV}, \mathrm{AES}$, prestaciones municipales. Si fuera necesario, servicio de infancia y familia, servicio de valoración y diagnóstico de la dependencia, servicio Hegoak, Banco de alimentos, Cáritas, etc.

Esta propuesta de plan de atención personalizada será contrastada con Nora, y si es posible, con Mohamed, para poder trabajar conjuntamente y llegar a un plan de trabajo compartido y consensuado, formalizado en un documento escrito y firmado por ambas partes.

La responsabilidad y los compromisos en el desarrollo de las acciones previstas en el plan serán compartidas entre la familia y el/la trabajador/a social, al margen de las gestiones derivadas de la puesta en marcha de servicios y prestaciones que por su naturaleza serán de responsabilidad profesional.
Este plan tendrá una duración de seis meses, periodo que contará con seguimiento y una vez finalizado se procederá a la revisión y evaluación.

Durante la ejecución del plan se realizará un seguimiento de las acciones en base a los objetivos establecidos, que se llevará a cabo fundamentalmente a través de contactos telefónicos, entrevistas sucesivas con Nora y Mohamed, visitas domiciliarias si fueran necesarias, reuniones de coordinación con las y los profesionales implicados/as e informes sociales de seguimiento, propios o de profesionales de otros servicios. Todo ello quedará registrado en el expediente facilitando el proceso de evaluación.

Este seguimiento permitirá una ejecución más flexible, adaptándose a las diferentes situaciones y acontecimientos no previstos en la planificación, sin perder de vista los objetivos fijados, pero introduciendo las modificaciones necesarias en el plan diseñado. También permitirá, en el caso de que se produzcan cambios importantes en la situación, iniciar una nueva valoración.

En el supuesto práctico, se plantea una evaluación de los resultados. Se trata de conocer el grado de consecución de los objetivos formulados a través de los indicadores de evaluación señalados en el diseño de la intervención. Se utilizarán las siguientes fuentes de información y los instrumentos de medida, por ejemplo: familia destinataria, profesionales intervinientes, expediente, registros, informes, etc. Una vez realizada la evaluación se decidirá, conjuntamente con la persona/familia, la reformulación del diseño de intervención o el cierre del caso. 
AGUILAR, M.J. (2013): Trabajo social. Concepto y metodología, Paraninfo y Consejo General de Trabajo Social, Madrid.

ALISEDA, F. (2019): Manual para la resolución de casos prácticos en trabajo social, Colegio Oficial de Trabajo Social de Badajoz, Badajoz.

ANDER-EGG, E. (1982): Metodología de trabajo social, El Ateneo, México.

CAMPANINI, A. y LUPPI, F. (1995): Servicio Social y Modelo Sistémico. Una nueva perspectiva para la práctica cotidiana, Paidós, Barcelona.

COLEGIOS OFICIALES DE TRABAJO SOCIAL (2012): Código deontológico de trabajo social, Consejo General de Trabajo Social, Madrid.

GOBIERNO DE ESPAÑA (2006): “Ley 39/2006, de 14 de diciembre, de Promoción de la Autonomía Personal y Atención a las personas en situación de dependencia”, Boletín Oficial del Estado, no 299, 15-12-2006, <https://www.boe.es/buscar/ act.php?id=BOE-A-2006-21990〉.

- (2018): “Ley Orgánica 3/2018, de 5 de diciembre, de Protección de Datos Personales y garantía de los derechos digitales", Boletín Oficial del Estado, no 294, 06-12-2018, 〈https://www.boe. es/buscar/doc.php?id=BOE-A-2018-16673'.

FEDERACIÓN INTERNACIONAL DE TRABAJADORES/AS SOCIALES (2018): Declaración global de principios del trabajo social, disponible en: 〈https://www.ifsw.org/declaracion-global-delos-principios-eticos-del-trabajo-social/>.

FERNÁNDEZ, T. y PONCE DE LEÓN, L. (2018): Trabajo social individualizado. Metodología de intervención, EDIASA, Madrid.

GARCÍA, F. (2001): La intervención profesional en trabajo social: supuestos prácticos I, Colegio Oficial de Trabajo Social de Málaga, Málaga.
GARCÍA, I. (2015): "Elaboración de un plan de trabajo y supuestos prácticos de intervención social”, en CRUZ, B.; BEMBIBRE, J. y BARRANCO, J. (coord.), Herramientas para la reflexión de la práctica de la intervención social, Genio Maligno, Granada, pp. 157-185.

GARCÍA, G. y RAMÍREZ, J. M. (2006): Manual práctico para elaborar proyectos sociales, Consejo General de Trabajo Social y Siglo XXI, Madrid.

GOBIERNO VASCO (2012): Informe final sobre la elaboración de un procedimiento básico de intervención en servicios sociales desde una perspectiva centrada en la persona, Departamento de Empleo y Asuntos Sociales, Vitoria-Gasteiz.

GUINOT, C. (2008): Métodos, técnicas y documentos utilizados en trabajo social, Universidad de Deusto, Bilbao.

KISNERMAN, N. (1998): Pensar el trabajo social: una introducción desde el construccionismo, Lumen-Humanitas, Buenos Aires.

MOSQUERA, M. P. (2014): Resolución de casos prácticos, Colegio Oficial de Trabajo Social de Cantabria, Cantabria.

PAÍS VASCO (2008): “Ley 12/2008, de 5 de diciembre, de Servicios Sociales", Boletín Oficial del País Vasco, nํ 246, 24-12-2008, <https://www. euskadi.eus/p43aBOPVWebWar/>.

- (2013): "Decreto 353/2013, de 28 de mayo, de Ficha Social del Sistema Vasco de Servicios Sociales y del instrumento de diagnóstico social del Sistema Vasco de Servicios Sociales", Boletín Oficial del País Vasco, nํㅡ 121, 26-06-2013, 〈https://www.euskadi.eus/ p43aBOPVWebWar/>.

- (2013): “Decreto 385/2013, de 16 de julio, por el que se aprueba el Instrumento de Valoración de la 
Exclusión Social, Boletín Oficial del País Vasco, n- 149, 07-08-2013, 〈https://www.euskadi.eus/ bopv2/datos/2013/08/1303530a.pdf〉.

- (2015): "Decreto 185/2015, de 6 de octubre, de cartera de prestaciones y servicios del Sistema Vasco de Servicios Sociales. Boletín Oficial del País Vasco, no 206, 19-10-2015, <https://www. euskadi.eus/bopv2/datos/2015/10/1504561a. pdf».

- (2017): "Decreto 152/2017, de 9 de mayo, por el que se aprueba la actualización del Instrumento para la valoración de la gravedad de las situaciones de riesgo y desamparo en los Servicios Sociales Municipales y Territoriales de Atención y Protección a la Infancia y adolescencia en la Comunidad Autónoma del País Vasco (BALORA)", n- 125, 03-07-2017, <https://www. euskadi.eus/bopv2/datos/2017/07/1703354a. pdf〉.

PASTOR, E. (2015): Trabajo social con comunidades, Universitas, Madrid.
RODRÍGUEZ, P. (2013): La atención integral y centrada en la persona, serie Papeles de la Fundación Pilares, no 1, pp. 1-114, 〈http://www.fundacionpilares. org/docs/AICPweb.pdf〉.

TORRADO, A. (2018): “Abordando la resolución de un caso práctico de intervención individual/familiar", TS Difusión, no 99, pp. 13-22, 〈http://www. tsdifusion.es/revistas_publicadas/99/pdf/ TSD99_3.pdf>.

VISCARRET, J.J. (2007): Modelos y Métodos de intervención en trabajo social, Alianza, Madrid.

- (2009): "Modelos de intervención en trabajo social", en FERNÁNDEZ, T. (Coord.), Fundamentos de trabajo social, Alianza, Madrid (pp. 293-344).

ZAMANILLO, T. (2008): Trabajo social con grupos y pedagogía ciudadana, Síntesis, Madrid.

- (2018): Epistemología del trabajo social. De la evidencia empírica a la exigencia teórica, Ediciones Complutense, Madrid. 